\title{
An eco-friendly and reusable antibacterial film-forming composite
}

\author{
Manonmani Mohandoss ${ }^{1,2 \#}$, Uthradevi Kannan ${ }^{1 \#}$, Gaurav Singhal ${ }^{1}$, AnithNelleri ${ }^{2}$ and \\ Shihabudheen M. Maliyekkal ${ }^{1 *}$
}
${ }^{1}$ Environmental Engineering Division, School of Mechanical and Building Sciences, VIT University, Chennai Campus, Chennai - 600 127, India
${ }^{2}$ School of Electronics Engineering, VIT University, Chennai Campus, Chennai - 600 127, India
VIT University, Chennai Campus, Chennai - 600 127, India
${ }^{\#}$ These authors contributed equally to this work
*Email: shihabudheen.m@vit.ac.in, sm.maliyekkal@gmail.com

\begin{abstract}
The growing awareness and environmental concerns have increased the demand for biocompatible and antibacterial materials for applications in biomedical, food packaging, water treatment, etc. This paper describes the development of an ecofriendly, transparent and reusable antibacterial film-forming composite. The composite essentially comprises of a biopolymer, silver nanoparticles (AgNPs) and reduced graphene oxide (RGO). Unlike conventional methods, the reduction of graphene oxide (GO) to RGO was done by exposing GO to sunlight (16 h) as an eco-friendly and energy efficient alternative. The inherent ability of RGO to reduce $\mathrm{Ag}^{+}$ion is exploited to produce welldispersed AgNPs of tuneable size on the surface of RGO sheets [1]. A redox like reaction between RGO and $\mathrm{Ag}^{+}$ions resulted in the formation of well dispersed AgNPs on RGO sheets (RGO-Ag). Large area antibacterial films were fabricated by introducing RGO-Ag dispersion into protonated chitosan solution $(2 \%)$ at $1: 1$ ratio. The careful evaporation of the solvent facilitated the formation of the film.The as-developed film was cross-linked by $5 \%$ tri-sodium citrate solution.
\end{abstract}

The composites were characterised by various spectroscopic and microscopic techniques. The enhanced antibacterial property of the film is demonstrated by disk diffusion test [2] using Escherichia coli (E. coli) as the model microbe.

RGO exhibits absorbance peaks at $260 \mathrm{~nm}$ and a shoulder at $302 \mathrm{~nm}$, which corresponds to the $\pi-\pi^{*}$ transition of $\mathrm{C}-\mathrm{C}$ bonds and $\mathrm{n}-\pi^{*}$ transition of $\mathrm{C}=\mathrm{O}$ bonds, respectively (Figure 1). The small hump around $400 \mathrm{~nm}$ is due to the surface plasmon resonance (SPR) absorption band of AgNPs. Formation of spherical AgNPs of around $70 \mathrm{~nm}$ on RGO-Ag is visible from Figure 2a. The enhanced antibacterial of ability of the nanocomposites is evident from the large zone of inhibition (Figure 2).

The film forming ability with high mechanical strength and enhanced antibacterial properties makes the composite a suitable candidate for diverse applications including food packaging and purification of water.

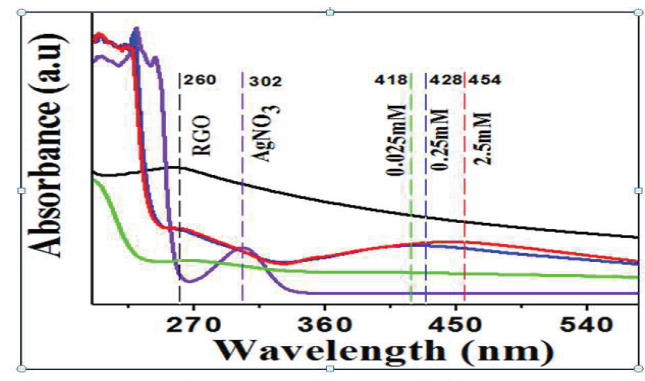

Figure 1: UV-Vis spectra of RGO and chitosan-RGO-Ag nanocomposites. Concentration of $\mathrm{Ag}^{+}$is varied $(0.025$ $\mathrm{mM}, 0.25 \mathrm{mM}, 2.5 \mathrm{mM})$. Spectral positions are marked in the figure.

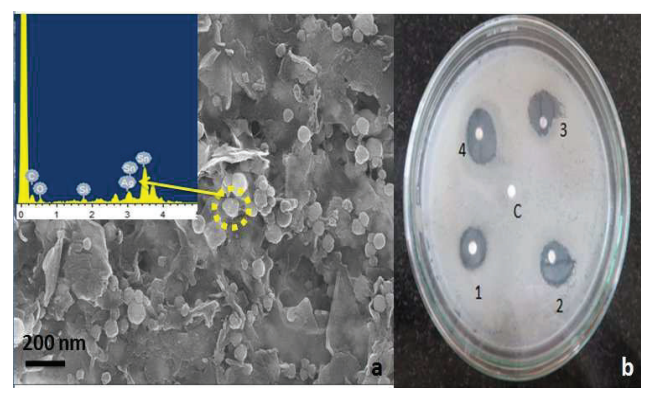

Figure 2: (a) FESEM micrograph of the chitosan-RGO-Ag nanocomposite. EDAX spectrum of the composite is shown the inset. (b): Photographs of disc diffusion assay represents the zone of inhibition. (1) only chitosan, (2) composite with (2) $0.025 \mathrm{mM} \mathrm{AgNO}$, (3) $0.25 \mathrm{mM}$ $\mathrm{AgNO}_{3}$, (4) $2.5 \mathrm{mM} \mathrm{AgNO}$.

Acknowledgements: Authors gratefully acknowledge Department of Science and Technology (DST), Government of India, Research and Development, Grant under Water Technology Initiative (WTI) for funding this work.

\section{References}

1. T. Sreeprasad, S.M. Maliyekkal, K. Lisha, T. Pradeep, Journal of hazardous materials 186 (2011) 921-931.

2. A. Bauer, W. Kirby, J.C. Sherris, M. Turck, American journal of clinical pathology 45 (1966) 493. 